\title{
Cultivo primário de células epiteliais germinativas do limbo de olhos doadores
}

\author{
Culture of limbal stem cells of donor eyes
}

Fabiana Amorim de Lima ${ }^{1}$

Magaly D'Angelo ${ }^{2}$

Homero Augusto de Miranda II $^{3}$

Sérgio Felberg ${ }^{1}$

Maria Cristina Nishiwaki-Dantas ${ }^{4}$

Paulo Elias Correa Dantas ${ }^{5}$
Trabalho realizado no Departamento de Oftalmologia da Santa Casa de Misericórdia de São Paulo - Seção de Córnea e Doenças Externas e Instituto Biológico de São Paulo.

Assistente do Setor de Córnea e Doenças Externas da Santa Casa de Misericórdia de São Paulo.

2 Doutora em Biologia pela Universidade de São Paulo USP; Chefe do Setor de Biologia Celular do Instituto Biológico de São Paulo.

${ }^{3}$ Assistente do Setor de Retina e Vítreo da Santa Casa de Misericórdia de São Paulo.

${ }^{4}$ Doutora em Oftalmologia pela Universidade Federal de São Paulo - UNIFESP; Chefe da Seção de Córnea da Santa Casa de Misericórdia de São Paulo.

${ }^{5}$ Doutor em Oftalmologia pela Universidade de São Paulo - USP; Chefe da Seção de Córnea, Doenças Externas e Refrativa do Hospital Oftalmológico de Sorocaba; Assistente do Setor de Córnea e Doenças Externas da Santa Casa de São Paulo.

Endereço para correspondência: Rua Clímaco Barbosa, 164 - casa 11 - São Paulo - SP - CEP 01523-000 E-mail: Fabianamorim@aol.com

Recebido para publicação em 01.02.2002 Aceito para publicação em 13.05.2002

Nota Editorial: Pela análise deste trabalho e por sua anuência na divulgação desta nota, agradecemos ao Dr. Paulo Ricardo de Oliveira

\section{R E S U M O}

Objetivo: Padronizar cultivo primário de células epiteliais germinativas do limbo de olhos doadores do Banco de Olhos da Santa Casa de São Paulo. Métodos: Por meio de biópsias de aproximadamente $4 \mathrm{~mm}^{2}$ realizadas na região do limbo cirúrgico do anel córneo-escleral remanescente de olhos doadores, foram obtidos explantes, que passaram por métodos de dissociação para obtenção de células epiteliais germinativas do limbo, as quais foram semeadas em placas de cultivo celular e encubadas na estufa a $37^{\circ} \mathrm{C} \mathrm{em}$ atmosfera a $5 \%$ de $\mathrm{CO}_{2}$. As placas foram observadas em 21 dias, sendo avaliadas a aderência, a morfologia e a multiplicação celular. Resultados: Observamos que as células no decorrer dos 21 dias multiplicaramse, passando da forma arredondada inicial ao processo de dissociação, para a forma poligonal como in vivo, além de demonstrarem maior aderência à placa de cultivo. Conclusão: Neste estudo foi possível demonstrar que o cultivo de células epiteliais límbicas in vitro pode ser realizado.

Descritores:Células cultivadas;Célulasepiteliais;Limbodacómea/citologia;Epitélioda cómea/ultra-estrutura;Aderênciacelular;Cómea/citologia;Transplantecelular

O epitélio corneal é um dos principais componentes da superfície ocular. Sua integridade e constante renovação são fundamentais para a manutenção da boa visão. É formado por epitélio escamoso estratificado, desprovido de células caliciformes, com camada basal de células cubóides apoiadas sobre a camada de Bowman. A córnea juntamente com a lágrima, é a principal responsável pelo poder refrativo do olho (43D), sendo de suma importância sua superfície manter-se uniforme. Segundo Thoft e Friends, criadores da Teoria $\mathrm{XYZ}^{(1)}$, o limbo constitui-se por um grupo de células epiteliais e germinativas distribuídas em camadas (e entre estas, células de Langerhans e melanócitos) e participa da renovação e manutenção desta superfície pela migração centrípeta destas células germinativas, que inicialmente desloca-se pelas camadas mais profundas do epitélio (X) e, à medida que se aproximam da região central da córnea tornam-se mais diferenciadas e ganham níveis mais superficiais (Y), até completarem seu ciclo vital entre 5 e 7 dias, descamando $(Z)^{(1-2)}$.

Algumas doenças que comprometem a superfície ocular e o filme lacrimal, como a síndrome de Stevens-Johnson, penfigóide ocular cicatricial, queimaduras químicas e térmicas, doenças imunológicas, ceratopatias induzidas por radiação, crioterapia no limbo (iatrogênica), processos infecciosos graves, dentre outras, levam à diminuição do número de células germinativas do limbo corneal. Nestas condições, o limbo perde sua função de barreira limitante entre as células conjuntivais e a córnea, instalando-se 
então, processo de conjuntivalização da córnea, característico de deficiência límbica. Tal processo manifesta-se com defeito epitelial crônico, erosões recorrentes, neovascularização, inflamação crônica e crescimento de tecido fibroso. A metaplasia escamosa, transição patológica do epitélio da superfície ocular não ceratinizado em ceratinizado, também é outro sinal de falência límbica ${ }^{(3)}$.

Como terapêutica atualmente aceita para esta falência límbica podemos encontrar a ceratoplastia penetrante, transplante de limbo ${ }^{(3)}$ e/ou transplante de membrana amniótica. Porém trata-se de técnicas com limitações, já que podem levar a rejeição ou exaustão do olho doador, no caso de doador vivo (autógeno ou homógeno).

A técnica ideal de reconstrução da superfície ocular seria aquela em que houvesse reposição autógena das células límbicas, sem a perda da maioria da população das células doadoras. Vários autores já demonstraram que suficientes células germinativas podem ser obtidas de biópsia do limbo de aproximadamente $2 \mathrm{~mm}^{2(4-13)}$ e após expandidas in vitro, serem transplantadas para o olho acometido, em alguns casos tendo como substrato a membrana amniótica humana. Esta técnica parece ser muito promissora, já que elimina o problema de tecido doador insuficiente, rejeição de transplantes homógenos e exaustão de células germinativas do olho doador.

Com estes princípios em mente, objetivamos estabelecer um cultivo primário de células epiteliais germinativas do limbo, obtidas de olhos doadores do Banco de Olhos da Santa Casa de São Paulo, abrindo assim novas perspectivas no estudo do tratamento da deficiência de limbo.

\section{MÉ T O D O S}

O projeto de pesquisa teve andamento após aprovação da Comissão de Ética da Santa Casa de São Paulo.

\section{Obtenção do tecido doador}

Para obtenção das células para o cultivo, foram realizadas biópsias, de aproximadamente $4 \mathrm{~mm}^{2}$, medidas com compasso cirúrgico, através da dissecção manual com a lâmina número 11, na região do limbo cirúrgico do anel córneo-escleral remanescente de olhos doadores, após retirada do botão doador da região central da córnea de olhos doadores liberados para transplante (Figura 2). Os explantes foram mantidos resfriados a $4^{\circ} \mathrm{C}$, no mesmo meio de manutenção da córnea doadora (Optisol), e transportados para o Laboratório de Biologia $\mathrm{Ce}$ lular do Instituto Biológico do Estado de São Paulo.

\section{Técnica de cultivo}

Na capela de fluxo laminar, o explante foi lavado em solução salina tamponada (PBS) a $4^{\circ} \mathrm{C}$, em placa de Petri. Em seguida foi levado para um dos "wells" de $16 \mathrm{~mm}$ de diâmetro da placa de policarbonato para cultivo celular e, fragmentado em pedaços menores com tesoura (primeira dissociação mecânica). $\mathrm{O}$ explante sofreu então dissociação enzimática sendo, adicionado a este disco DMEM (Meio de Dulbeco Modifica- do) contendo $1,2 \mu \mathrm{g} / \mathrm{ml}$ de Dispase II em estufa a $37^{\circ} \mathrm{C}$ por 90 minutos. Em seguida a enzima foi neutralizada com DMEM contendo SFB a $10 \%$. Transferido para outro "well" vazio da mesma placa, os pequenos pedaços de explante sofreram então a segunda dissociação mecânica pela pipetagem de solução salina livre de cátions de cálcio e magnésio (Citrato).

Os explantes foram submetidos à centrifugação a $800 \mathrm{~g} /$ 5 min, e as células obtidas ressuspensas em SHEM, que é a combinação dos meios DMEM e HAM'S F12 (1:1 vol/vol), acrescido de insulina $(5 \mu \mathrm{g} / \mathrm{ml})$, toxina colérica $(0,1 \mu \mathrm{g} / \mathrm{ml}), \mathrm{EGF}$ a $20 \mathrm{ng} / \mathrm{ml}$ e Soro Fetal Bovino (SFB) a 20\%, semeadas em outro well da placa, e cultivadas na estufa a $37^{\circ} \mathrm{C} \mathrm{em}$ atmosfera a 5\% CO 2. A figura 1 resume em forma de fluxograma, a metodologia de cultivo aplicada.

\section{Método de avaliação}

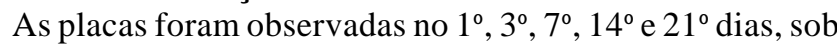
microscopia óptica direta, modelo Olimpus-Tokyo, com aumento de 10 e 100 vezes, e fotografadas com filme Fujichrome Asa 50, avaliando-se os seguintes fatores:

- Aderência das células à placa de cultivo.

- Morfologia celular (Forma arredondada não aderida ou poligonal, como originalmente é observada in vivo)

- Multiplicação celular (Pelo preenchimento de espaços vazios na placa - monocamada, e capacidade de formação de colônias, através da observação individualizada de uma célula e sua multiplicação por consecutivas mitoses). A observação de colônias foi feita pela marcação de uma região da placa de cultivo com caneta hidrográfica, acompanhando um agrupamento celular originado de uma única célula.

RES U L T A D O S

Na região da placa demarcada por caneta observamos a formação de agrupamento celular com mais de 40 células oriundas de uma única célula mãe.

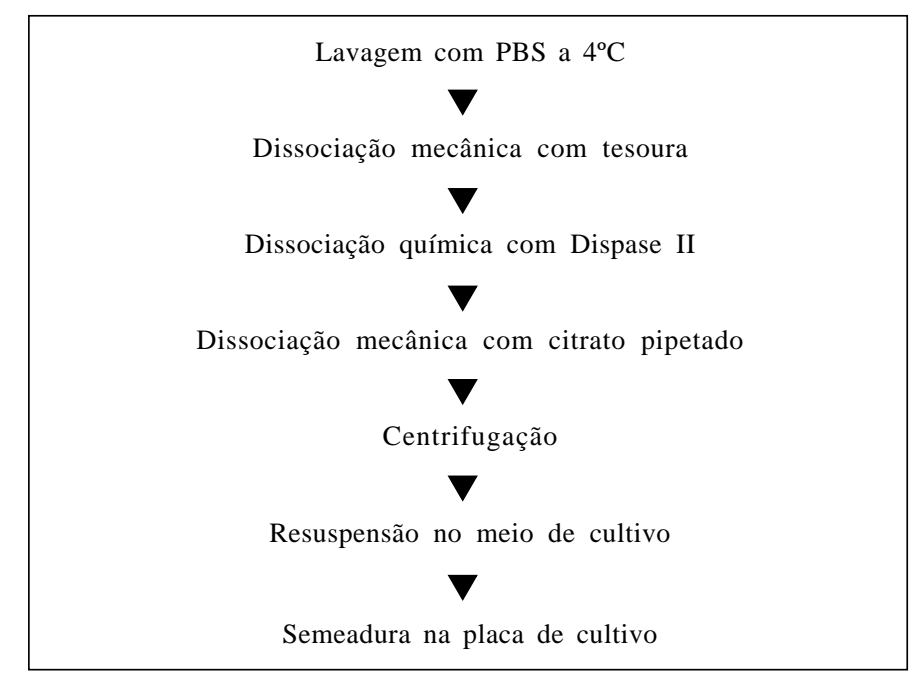

Figura 1 -Fluxograma do método de cultivo de células epiteliais germinativas dolimbo 
O quadro abaixo resume o resultados das nossas observações:

\begin{tabular}{|c|c|c|c|c|}
\hline \multicolumn{5}{|c|}{$\begin{array}{l}\text { Quadro 1-Resultados obtidos da observação do cultivo de } \\
\text { células epiteliais germinativas do limbo de olhos doadores } \\
\text { humanos por } 21 \text { dias, no Instituto Biológico do Estado de } \\
\text { SãoPaulo, } 2000\end{array}$} \\
\hline & 10dia & $\begin{array}{c}\text { 39dia } \\
\text { (Figura 2) }\end{array}$ & 79dia & \\
\hline cia & Não & Parcial & & \\
\hline Morfologia & Arredondada & Ovalada & Poligonal & Poligonal \\
\hline Multiplicação & Não & Sim & Sim & Pouca \\
\hline
\end{tabular}

D I S C U S S ÃO

O desenvolvimento de tecidos e órgãos em laboratório para transplante em seres humanos está passando do campo da ficção científica para realidade. A necessidade da obtenção de novas técnicas que supram as falhas dos tratamentos já consagrados de deficiência límbica fez com que técnicas de cultivo celular fossem aprimoradas e, a bioengenharia desenvolvesse tecidos humanos em laboratório passíveis de serem transplantados.

A doença ocular caracterizada pela deficiência límbica tem terapêutica apoiada na reposição de células germinativas do limbo. O transplante de membrana amniótica é indicado com a intenção de recuperar o estroma do limbo afetado ${ }^{(14)}$, e desta forma, proporcionar um ambiente adequado à multiplicação das células límbicas remanescentes, enquanto o transplante de limbo restauraria a população de células germinativas. Até agora, este tipo de tratamento baseia-se no transplante cirúrgico de blocos de tecido límbico contendo células germinativas. Kenyon e Tseng ${ }^{(14)}$ foram os pioneiros da técnica do transplante autógeno de limbo, na qual segmentos de limbo são retirados do olho sadio contralateral para serem transplan-

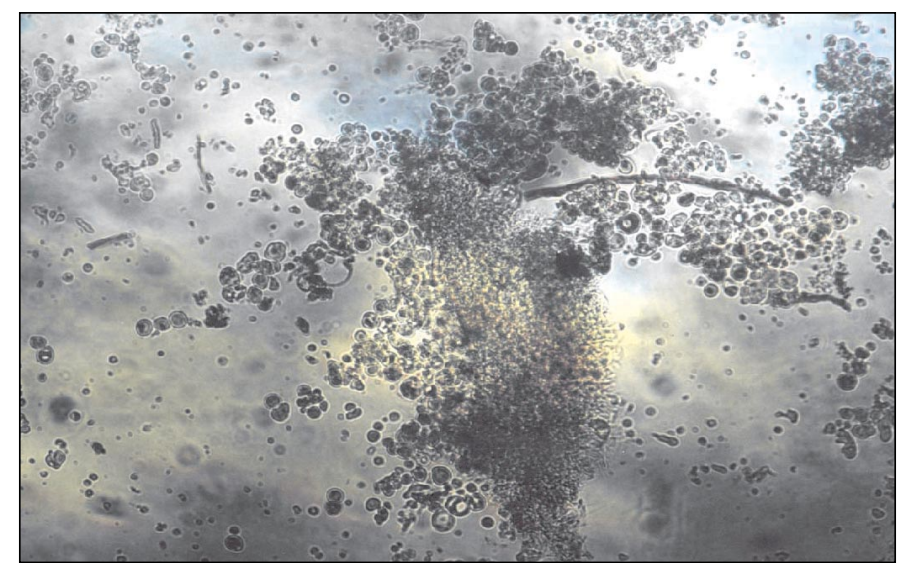

Figura 2 -Células epiteliais germinativas do limbo, fotografadas no 39 diadecultivo, mostrandocélulas arredondadas, parcialmenteaderidas epróximasaoexplantelocalizadonaregiáocentraldafigura (microscopiaopticadiretacomaumentode 100 vezes)

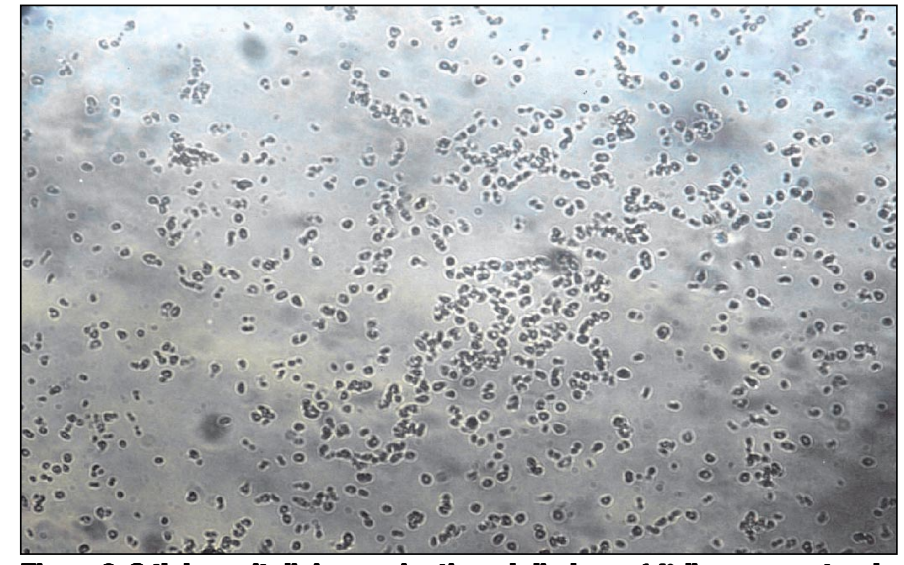

Figura3-Célulasepiteliaisgeminativasdolimbono140lia, apresentando aspectopoligonal, aderidas aofundoda placadecultivo,jáformandoa monocamada, fotografadassobmicroscopiáópticadiretaemaumento de 10vezes

tados para o olho acometido. Entretanto, é uma técnica que pode colocar o olho doador em risco, já que estes blocos retirados têm dimensões de até metade da circunferência límbica doadora ${ }^{(15)}$, levando as células remanescentes à exaustão. Tratamentos alternativos, como o transplante homógeno, tanto de doadores vivos como de cadáveres, também têm suas limitações, como a necessidade de imunossupressão a longo prazo, material cadavérico doador sem condições ideais para transplante, ou pelos mesmos motivos do transplante autógeno, quantidade de tecido insuficiente ou o acometimento do olho doador sadio.

A técnica ideal de reconstrução da superfície ocular seria aquela que promove a reposição autógena das células límbicas, sem a perda da maioria da população das células do limbo doador. Pensando em minimizar o tamanho do tecido autógeno doador, técnicas de cultivo e expansão in vitro vêm sendo desenvolvidas ${ }^{(4-9,11)}$. O cultivo de diversos tipos de células vegetais e animais é bem difundido em nosso país, com as mais variadas finalidades, desde testes da toxicidade de agrotóxicos até a fertilização in vitro. Porém desenvolver técnica para algum tipo específico de célula, com suas necessidades particulares é um trabalho árduo. Existem diversos trabalhos publicados sobre o cultivo de células límbicas, porém nenhum com informações suficientes para a exata reprodução do experimento ${ }^{(4-9,11)}$. Além disto, não dispomos de todos os ingredientes citados nestes trabalhos, sendo necessária a importação destes produtos com seus elevados custos financeiros.

Condições peculiares são necessárias para que cada tipo de célula se multiplique. Muitos aspectos do sistema de cultivo que nada têm a ver com a composição do meio de cultura podem afetar o crescimento: a concentração da população de células, adesão ao substrato e a natureza deste, maneira pela qual as células são manipuladas durante os repiques, etc. Por esta razão, o meio deve fornecer às células, além de todos os nutrientes essenciais, ambiente que se assemelhe ao máximo àquele que dispunham in vivo. Um meio de cultivo típico contém vários nutrientes de baixo peso molecular dissolvidos em solução salina tamponada e deve apresentar características 
físico-químicas que permitam a sobrevivência e multiplicação celular. Alguns parâmetros importantes são: temperatura, concentração hidrogeniônica $(\mathrm{pH})$, tensão de $\mathrm{CO}_{2}$, osmolaridade, tampões e tensão de $\mathrm{O}_{2}$.

A elaboração deste estudo resultou de uma série de experiências e adaptações às diferentes condições citadas na bibliografia do assunto. Neste experimento, a presença de células germinativas no cultivo de células límbicas foi confirmada pela eficiência de formação de colônia de vários agrupamentos celulares. Somente células germinativas são capazes de estabelecer colônias com mais de 40 células a partir de uma célula progenito$\mathrm{ra}^{(12)}$. Células do epitélio da córnea e da conjuntiva não são capazes de estabelecer cultura por mais de 14 dias, pela perda da capacidade de multiplicação e aderência, ao adquirirem características de senescência e vacuolização. A utilização desta técnica de avaliação, e não do uso de marcadores indiretos de células límbicas, que podem contribuir para o melhor controle do grau de pureza do cultivo, foi devido à impossibilidade da importação dos marcadores histoquímicos de células epiteliais germinativas, pelo seu elevado custo financeiro.

C ONCLUS ÃO

Neste estudo foi possível demonstrar que o cultivo de células epiteliais límbicas ex vivo pode ser realizado, porém estes resultados são apenas um passo inicial para estabelecermos melhor tratamento em pacientes com deficiência límbica das mais variadas causas. A sequiência lógica do nosso estudo é estabelecer um substrato adequado (membrana amniótica, lentes de contato comuns ou de colágeno), para o transporte destas células para a superfície ocular comprometida e, até mesmo o desenvolvimento de tecido biossintético a partir de uma única célula germinativa, capaz de substituir todos os componentes da córnea.

A B S T RAC T

Purpose: Standardization of limbal stem cell culture of donor eyes from Eye Bank of the "Santa Casa de São Paulo". Methods: a $4-\mathrm{mm}^{2}$ biopsy was taken from the remaning corneal-scleral ring of donor eyes, and cells obtained by dissociation were cultivated and incubated at $37^{\circ}$ under $5 \% \mathrm{CO}_{2}$. The cells were observed during 21 days, evaluating their cell adhesion, morphology and multiplication. Results: We observed cellular multiplication, morphology modification during 21 days, passing from round to polygonal form, as in vivo. Conclusion: This experiment showed that culture of human limbal stem cells in vitro can be performed.

Keywords: Cultured cells; Epithelial cells; Limbus corneae/ cytology; Corneal epithelium/ultrastructure; Cell adhesion; Cornea/cytology; Cell transplantation

\section{REFER ÊNCIAS}

1. Thoft RA, Friend J. The X, Y, Z hypothesis of corneal epithelial maintenance. Invest Ophthalmol Vis Sci 1983;24:1442-3.

2. Dua HS, Forrester JV. The corneoscleral limbus in human corneal epithelial wound healing. Am J Ophthalmol 1990;110:646-5.

3. Pellegrini G, Traveso CE, Franzi AT, Zingirian M, Cancedda R, De Luca M Long term restoration of damaged corneal surfaces with autologous cultivated corneal epithelium [commented on Lancet 1997;349:1556]. Lancet 1997; 349:990-3.

4. Ebato B, Friend J, Thoft RA. Comparison of central and peripheral human corneal epithelium in tissue culture. Invest Ophthalmol Vis Sci 1987 28:1450-6.

5. He YG, Alizadeh H, Kinoshita K, McKculley JP. Experimental transplantation of cultured human limbal and amniotic cells onto the corneal surface. Cornea 1999;18:570-9.

6. Kim JC, Tseng SCG. Transplantation of preserved human amniotic membrane for surface reconstruction in severely damaged rabbit corneas. Cornea 1995; $14: 473-84$.

7. Koizumi N, Inatomi T, Quantock AJ, Fullwood NJ, Dota A, Kinoshita S. Amniotic membrane as substrate for cultivating limbal corneal epithelial cells for autologous transplantation in rabbits. Cornea 2000;19:65-71.

8. Kruse FE, Tseng SCG. Retinoic acid regulates clonal growth and differentiation of cultured limbal and peripheral corneal epithelium. Invest Ophtalmol Vis Sci 1994;35:2405-20.

9. Kruse FE, Tseng SCG. Serum differentially modulates the clonal growth and differentiation of cultured limbal and corneal epithelium. Invest Ophthalmol Vis Sci 1993;34:2976-89.

10. Kruse FE, Tseng SCG. Growth factors modulate clonal growth and differentiation of cultured rabbit limbal and corneal epithelium. Invest Ophthalmol Vis Sci 1993;34:1963-76.

11. Meller D, Tseng SCG. Conjuntival epithelial cell differentiation on amniotic membrane. Invest Ophthalmol Vis Sci 1999;40:878-86.

12. Pires RTF, Pires JLTF, Tseng SCG. Transplante de membrana amniótica para a reconstrução da superfície corneana e conjuntival. Arq Bras Oftalmol 1999;62:340-50.

13. Schwab IR, Reyes M, Isseroff RR. Successful transplantation of bioengineered tissue replacement in patients with ocular surface disease. Cornea 2000; 19:421-6.

14. Kenyon KR, Tseng SCG. Limbal autograft transplantation for ocular surface disorders. Ophthalmology 1989;96:709-22; discussion p.722-3.

15. Hodson S. Cultivating a cure for blindness. Nature 1997;387:449.

\section{Ao enviar um artigo para publicação, leia ATEN TAMENTE as instruções para autores, constante no final de cada fascículo.}

